\title{
Do traditional Birth Attendants (TBAs) Have a Role in the Prevention of Neonatal Tetanus
}

\author{
Jalal-Eddeen Abubakar Saleh ${ }^{1, ~ *, ~ A b d u l l a h i ~ H a m i s u ~ W a l l a ~}{ }^{2}$, Usman Saidu Adamu ${ }^{3}$ \\ ${ }^{1}$ W.H.O. Bauchi Zonal Office, Bauchi State, Nigeria \\ ${ }^{2}$ W.H.O. Country Office, Abuja, Nigeria \\ ${ }^{3}$ NPHCDA, Northeast Zonal Office, Bauchi, Nigeria \\ Email address: \\ drjalals@yahoo.com (J. A. Saleh)
}

\section{To cite this article:}

Jalal-Eddeen Abubakar Saleh, Abdullahi Hamisu Walla, Usman Saidu Adamu. Do traditional Birth Attendants (TBAs) Have a Role in the Prevention of Neonatal Tetanus. American Journal of Health Research. Vol. 3, No. 3, 2015, pp. 189-193. doi: 10.11648/j.ajhr.20150303.24

\begin{abstract}
Background: In spite of the significant achievement of the global NNT elimination campaign and with the deadline set at 2015, NNT is still among the leading causes of death in 25 developing countries. Additionally, the sub-Saharan African region still has the lowest coverage of Antenatal care services and hospital deliveries. Study Design: Retrospective study Methods: Quantitative cross-sectional involving mothers of NNT children using secondary data collected between January 2008 and December 2013 from northeastern Nigeria. Results: The result shows that a significant difference existed between mothers that delivered with the help of TBAs and those that did not; z-statistic $(\mathrm{N}=171)=5.278, \mathrm{p}<.001 ; 95 \%$ confidence interval $(\mathrm{CI})=0.235$ to 0.371 . Conclusion: The Nigerian government should prioritize its activities to give quality training to the TBAs to help in the delivery of pregnant women who reside especially in the rural underserved communities.
\end{abstract}

Keywords: Antenatal Care, Neonatal Tetanus, Traditional Birth Attendants, Umbilical Cord Care

\section{Introduction}

Neonatal tetanus (NNT), one of the most underreported diseases in the developing countries, is a deadly vaccinepreventable disease that is seen in the newborn within the first 28 days of life. The disease is one of the leading causes of deaths among neonates in the under-developed countries of the world with about 130,000 neonatal deaths recorded in $2004^{1,2}$. NNT, caused by Clostridium tetani bacteria found especially in soil, dust and animal feces, has a high case fatality rate of at least $70 \%$, with worst cases seen in especially pregnant mothers and the newborn ${ }^{1}$. In spite of the significant achievement of the global NNT elimination campaign and plans to reduce infant mortality rates across the globe by 2015 as enshrined in the millennium development goal item four ${ }^{3}$, NNT is still among the leading causes of death in 25 developing countries. Literature has shown that there are at least 355,000 cases of neonatal tetanus across the globe annually, resulting in about 250,000 deaths $^{3}$.

The prevalence of NNT in the developing countries is higher in the underserved communities that have lower social status, lack educational background, have low per capita income, and lack access to quality healthcare. Additionally, health inequity, poverty, illiteracy, cultural barriers, and beliefs, results in unhygienic birth practices. The resultant effect of these is the exposure of the umbilical cord to the tetanus bacteria ${ }^{1,2,4,5}$.

Although it is estimated that only $5 \%$ of cases are reported to the health services, especially within the underdeveloped countries, it is clear that significant achievement has been made in the current global fight against NNT. This is as evidenced by the reduction in the number of NNT. While MNT was prevalent in both middle and low-income countries of the world, global figure shows that there was a remarkable reduction in the prevalence rate from 57 in 1999 to 25 as of December 2013. Additionally, in 2010, the WHO estimated that there was a significant reduction in the NNT neonatal death rates to about 58,000 newborns; this figure shows a $93 \%$ reduction in neonatal death rates from NNT when compared with neonatal death rates recorded in the $1980 \mathrm{~s}^{6,7,8}$.

In an attempt to address the problem of inadequate vaccine coverage among pregnant women and women of 
childbearing age, and towards achieving the elimination strategy, in 1997 the Nigerian government replaced the expanded program on immunization with the national program on immunization ${ }^{9}$. It was observed that this change did not yield significant differences in the prevalence and case fatality rates of NNT. The NNT case-based surveillance established by the WHO is aimed at investigating individual records of suspected NNT cases ${ }^{10}$.

Although child mortality rate has dropped by more than a third globally, the progress is rather slow as to meet with the 2015 target. This situation is especially true in the subSaharan Africa and Southern Asia regions because of there were up to 6.2 million child deaths in 2010 from these two regions, which is about $82 \%$ at a global scale ${ }^{11}$.

The sub-Saharan African region still has the lowest coverage of ANC and hospital deliveries; this is notwithstanding the fact that between 1990 and 2010 there was a recorded increase from $55 \%$ to $65 \%$ in the proportion of deliveries attended by skilled health personnel in the developing countries ${ }^{11}$. Ironically, figures in 2010 showed that about half of the pregnant women in the sub-Saharan African region did not have the WHO recommended minimum of four ANC visits. Although figures from Southern Africa shows almost universal coverage in 2010, the story was far different in the West African region with nearly a third of pregnant women are without having access to $\mathrm{ANC}^{11}$. Furthermore, the small proportion of mothers who received the ANC visits did not get the minimum required quality of care ${ }^{11}$. In a community-based survey conducted to assess the incidence of NNT, the outcome clearly shows NNT as a major contributor to neonatal deaths. The two main factors attributed to this include erosion of confidence in immunization by parents and lack of clean quality deliveries by those who deliver at home ${ }^{12}$.

The standard NNT case definitions used in this study is that any newborn who was able to breastfeed in the first 2-3 days of life and suddenly became irritable and could not breastfeed, and die within the first 28 days of life, or any death of a newborn child within the first 28 days of life for unexplained reasons ${ }^{22}$. The term traditional birth attendant (TBA), as used in this study, is any person that assists mothers during childbirth and initially acquired her skills by delivering babies herself or through apprenticeship to other $\mathrm{TBAs}^{23}$. Traditional birth attendants, trained or not, are excluded from the category of a skilled attendant at delivery ${ }^{22}$.

Nigeria, where this study is conducted, is a secular country that gained independence from the Great Britain on October 1, 1960. Nigeria, with an estimated population of $180,049,322$, is considered as the most populous country in Africa $^{24}$. With a birth rate of 38.03 births/1,000 population and a death rate of 13.16 deaths $/ 1,000$ population Nigeria is rated as 12th and 19th in the world (2014 est.) respectively. Additionally, the Maternal Mortality Rate (MMR) stands at 630 deaths/100,000 live births (2010), which is 11th in the world and the Infant Mortality Rate (IMR) at 74.09 deaths $/ 1,000$, which is 10 th in the world. The country's health expenditure as at 2011 was $5.3 \%$ of GDP that is 127 th in the world, with 0.4 physicians/1,000 population (2008), and hospital bed of 0.53 beds $/ 1000$ population ${ }^{13,14}$.

Nigeria, which is broadly divided into the south and north regions, has six geopolitical zones - north central, northeast, northwest, southeast, south-south and southwest. The northeast sub-region, which comprises of six states (Adamawa, Bauchi, Borno, Gombe, Taraba, and Yobe), is less densely populated and well known for the production of crops and livestock. The northeast sub-region, when compared with the southern region, has poorer and worse health outcomes ${ }^{14}$. The north and south regions have different socioeconomic status, cultural and religious practices; this could explain the differences in the prevalence of the vaccine preventable diseases between these regions. In the north, there are $90.1 \%$ of women who are more likely to deliver at home as compared to $22.5 \%$ in the south. Furthermore, births attended to by a skilled professional in the southern region are about $81.8 \%$ in comparison with as low as $9.8 \%$ in the north ${ }^{13,14}$.

\section{Methodology}

This retrospective cross-sectional quantitative study used NNT dataset collected from 2008 - 2013 that involve 312 participants who are mothers of NNT babies. In line with the standard NNT case definition, the criterion used in the selection of the participants is that all mothers who gave birth to newborn babies within the first 28 days of life. The authors arrived as to whether participants were attended to by TBAs using the outlined questions on the standard NNT case investigation tool.

The NNT data was collected from eligible participants in the northeast region using a standard tool. Informed of consent of the participants was obtained from the local authorities and the husbands of these women prior administering the questionnaire. The participants were well informed in the local language that they understood on the purpose of administering the questionnaire. The information obtained was securely kept in the official database, and restricting data access except to authorize persons.

The instrument used for collecting data from the respondents has on its various columns the following: the first column for capturing demographic information of the NNT child, as well as that of the parents. Other columns are tailored to obtain information on the mother's vaccination history, birth of an infant, initial clinical history, treatment, action taken in the form of response, and final classification of the case. To ensure that the outcome is valid and generalizable, quality of the items was sought with content validity. The content of the instrument clearly measures what it was expected to measure; thus validity and reliability of the measurement instrument was well tested $^{15,16}$. 


\section{Results}

The research used SPSS version 22 to conduct single sample proportions test to determine if significant differences in frequency of receiving the attention from trained traditional birth attendants existed between mothers that indicated receiving treatment and those that did not. The results from the test indicated that a significant difference did exist; $z$-statistic $(\mathrm{N}=171)=5.278, \mathrm{p}<.001$; $95 \%$ confidence interval $(\mathrm{CI})=.235$ to .371 . Thus, mothers giving birth to NNT babies reported significantly fewer incidences of receiving care from trained attendants. The figure displayed below shows the status of mothers who gave birth to NNT babies attended by trained TBA care; it compared the differences between mothers that reported receiving midwife care at delivery compared to mothers who did not.

It is interesting to note that while result of the single sample proportions test showed a significant difference in frequency of receiving the attention from trained traditional birth attendants existed between mothers that indicated receiving treatment and those that did not, there was no such difference when a comparison is made between the six provinces $(p=.344)$ in the northeast region as shown in Chi-squared Tests of Independence displayed in Table 1.

Table 1. Chi-squared Tests of Independence.

\begin{tabular}{lllll}
\hline Variable & $\begin{array}{l}\text { Pearson Chi- } \\
\text { Square }\left(\chi^{2}\right)\end{array}$ & df & Sig. (p) & Cramer's V \\
\hline Attended by TBA & 5.626 & 5 & .344 & .181 \\
\hline
\end{tabular}

\section{Discussions}

The findings form this study indicated that significant difference did exist as mothers who gave birth to NNT babies reported significantly fewer incidences of receiving care from trained TBAs. This finding is consistent with other research findings that delivery of newborn babies by untrained and unskilled traditional birth attendants (TBA) are factors to mothers giving birth to NNT babies ${ }^{17-20}$. Additional studies showed that the unhygienic birth practices by some women such as cutting of the umbilical cord with unsterilized or contaminated sharp instruments are other contributing factors to neonates developing $\mathrm{NNT}^{17-21}$.

In consideration to the importance of vaccination against infectious diseases, researchers have observed that declining TT vaccine coverage among pregnant women and women of childbearing age are significant contributors to the high incidence of NNT in Nigeria ${ }^{5,20}$. Thus, there is the need for policy makers and public health specialists to underscore the significance of stakeholder participation in the area of routine immunization of pregnant women and to emphasize on the need for school-based immunization among girls. In addition to these, policy makers should ensure the need for supplementary immunizations, increase community awareness on NNT, the retraining of TBAs/other alternative care providers, and easing access of all pregnant women to quality health care services ${ }^{5,17,20}$. However, achieving these clearly requires the need to have a clear understanding of the beliefs of women on outcomes of getting tetanus toxoid vaccination, their attitude towards the tetanus toxoid vaccine, their normative beliefs, as well as their control beliefs.

Although the Nigeria's economy was rebased in April 2014, which placed the country as Africa's largest economy as a result of its 2013 GDP estimated at US\$ 502 billion, it is disheartening to note that the economic diversification and strong economic growth could not translate into a meaningful decline in poverty levels as the country's health indicators are considered among the worst across the globe. In spite the strategic role that Nigeria plays on the African continent, the government has failed to uphold the goals of the universal basic primary health care; this made the healthcare system operating below the minimum expected standard. In consideration of the fact that the global NNT elimination deadline and the timeline for achieving MDG goals 4 and 5 is 2015, there is need for the Nigerian government to show extra commitment to work with other partner agencies that work in addressing neonatal mortality. The noble goal of improving on both maternal and neonatal death rates should be considered sacrosanct by the public health leadership in Nigeria as well as the other remaining NNT endemic countries so as to improve on the health indicators $^{13,25}$.

\section{Conclusions}

In conclusion, there is need for public health specialists, policy makers, and healthcare providers to create awareness about the importance of pregnant mothers attending ANCs, to give quality training to the TBAs on safe home deliveries/educate mothers on hygienic handling the umbilical cord of the newborns, and to train additional health professionals that would render quality antenatal care services to especially the rural populace. There is no doubt that these measures would influence/promote social change in the community and also improve Nigeria's health indicators. 


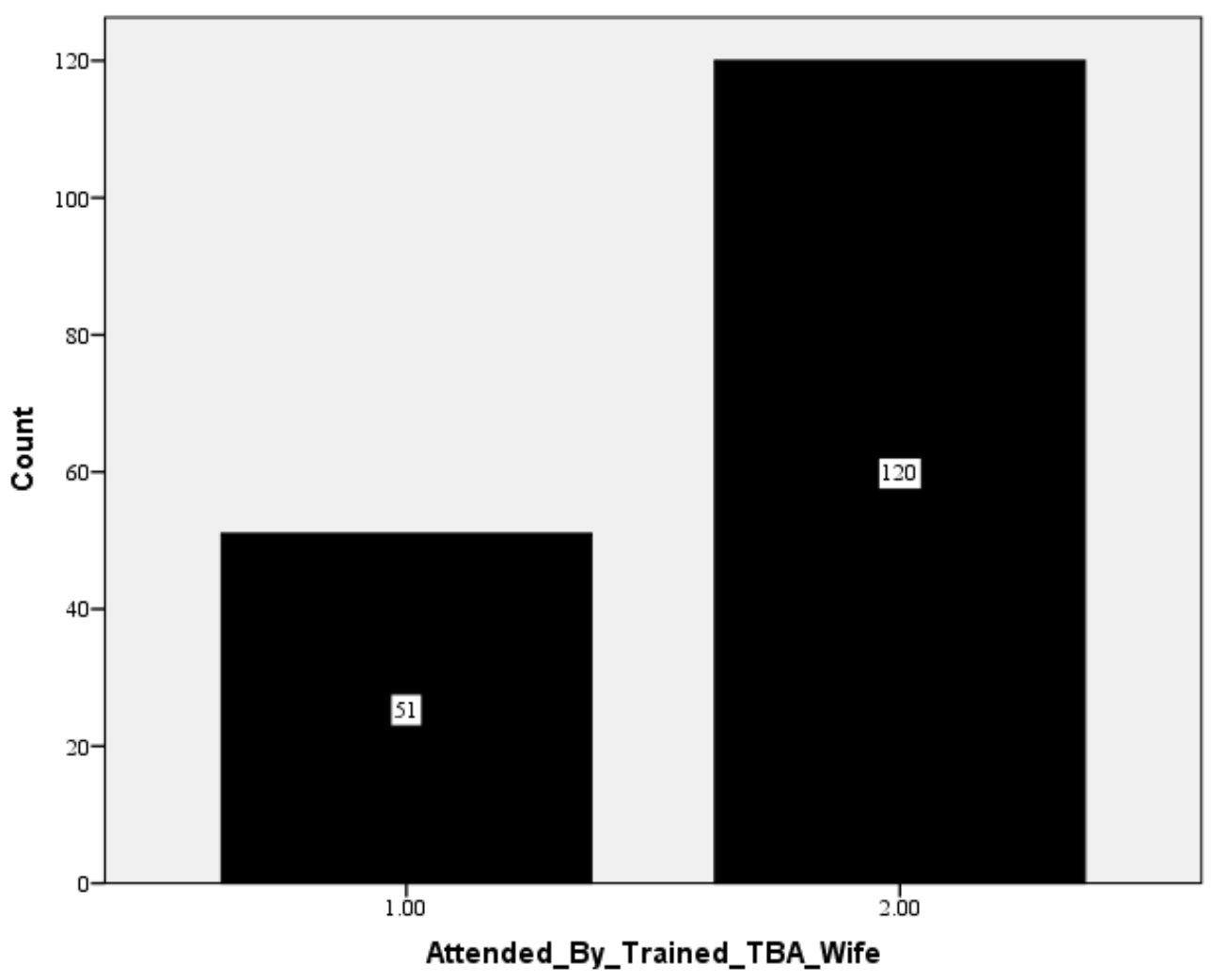

Fig. 1. Mothers who gave birth to NNT babies attended by trained TBA care status

\section{Acknowledgments}

The authors obtained ethical approval for the use of secondary data for this research from the Nigerian NPHCDA. There is no funding, royalty or conflict of interest declared.

\section{References}

[1] WHO (2004). "The Global Burden of Disease 2004 Update" Retrieved http://www.who.int/healthinfo/global_burden_disease/2004_re port_update/en/index.html.

[2] Roper, M. H., Vandelaer, J. H., \& Gasse, F. L. (2007). Maternal and neonatal tetanus. Lancet, 370, 1947-59.

[3] MDG (2013). MDGs in Nigeria - Current Progress. Retrieved from http://www.ng.undp.org/mdgsngprogress.shtml.

[4] Ogunlesi, T. A. (2011). Vaccines for women to prevent neonatal tetanus: RHL commentary. The WHO Reproductive Health Library; Geneva: World Health Organization. Retrieved from http://apps.who.int/rhl/newborn/cd002959_Ogunlesit_com/en/

[5] Akani, N. A., Nte, A. R., \& Oruamabo, R. S. (2004). Neonatal tetanus in Nigeria: One social scourge too many! Nig $\mathrm{J}$ of Paediatrics, 3, 1-9. Retrieved from http://www.ajol.info/index.php/njp/article/viewFile/12080/1519 8 .

[6] UNICEF (2014). Elimination of maternal and neonatal tetanus. Retrieved from http://www.unicef.org/health/index_43509.html.
[7] UNICEF, WHO, UNFPA (2000). Maternal and neonatal tetanus elimination by 2005. Strategies for achieving and maintaining elimination. Retrieved from http://www.unicef.org/health/files/MNTE\%5Fstrategy\%5Fpap er.pdf.

[8] WHO (2014). Maternal and Neonatal Tetanus (MNT) elimination: The initiative and challenges. Retrieved from http://www.who.int/immunization/diseases/MNTE_initiative/e $\mathrm{n} /$.

[9] Awosika, A. (2000). Boosting routine immunization in Nigeria: issues and proposed action points. Retrieved from http://www.afro.who.int.ezp.waldenulibrary.org/ddc/vpd/2000t fi:/.

[10] Fetuga, M., Ogunlesi, T., Adekanmbi, A., Runsewe-Abiodun, T., \& Ogunfowora, O. (2009). Neonatal tetanus in Sagamu, Nigeria during the Expanded Programme on Immunization and the national programme on immunization eras: a comparative analysis. The Internet Journal of Pediatrics and Neonatology, 12(1). Retrieved from https://ispub.com/IJPN/11/2/5040.

[11] The MDG Report (2012). We can end poverty 2015. UN Publication, New York. Retrieved from http://www.endpoverty2015.org/en/category/millenniumdevelopment-goals/.

[12] WHO (2007). Weekly Epidemiological Record. No. 46(81) 433-444 Retrieved from http://www.who.int/wer.

[13] Central Intelligence Agency (2014). The World Fact book: Country Comparison. Retrieved from https://www.cia.gov/library/publications/the-worldfactbook/geos/ni.html. 
[14] Nigeria Demographic and Health Survey (2008): North East. UNICEF 2009 Publication. Retrieved from http://www.unicef.org/nigeria/ng publications North East zo nal_fact_sheet_(English).pdf.

[15] Frankfort-Nachmias, C., \& Nachmias, D. (2008). Research methods in the social sciences (7th ed.). New York: Worth.

[16] Szklo, M., \& Nieto, F. J. (2014). Epidemiology: Beyond the basics (3rd ed.). Sudbury, MA: Jones and Bartlett.

[17] Blencowe, H., Lawn, J., Vandelaer, J., Roper, M., \& Cousens, S. (2010). Tetanus toxoid immunization to reduce mortality from neonatal tetanus. Int J of Epidemiology, 39, i102-i109. doi:10.1093/ije/dyq027.

[18] Afshar, M., Raju, M., Ansell, D., \& Bleck, T. P. (2011). Narrative review: tetanus-a health threat after natural disasters in developing countries. Ann Internal Medicine, 154, 329-35; PMID:21357910.

[19] Zafar, F., Rasheed, J., \& Abdulghaffar, H. (2012). Neonatal Tetanus. Professional Med Journal, 19(6), 773-781. Retrieved from http://www.theprofesional.com/article/vol-19-no06/prof-1962.pdf.

[20] Sani, M. N., Galadima, M., Ameh, J. B., Kawo, A. H. \& Kurawa, S. M. (2010). Serological evaluation of protective immunity against tetanus in pregnant women attending some rural hospitals in Kano, northern Nigeria. Bayero Journal of Pure and Applied Sciences, 3(1), 39-42. Retrieved from http://ecc.isc.gov.ir/ShwFArticle.aspx?aid=594864.

[21] Alhaji, M. A., Bello, M. A., Elechi, H. A., Akuhwa, R. T., Bukar, F. L., \& Ibrahim, H. A. (2013). A review of neonatal tetanus in University of Maiduguri Teaching Hospital, northeastern Nigeria. Niger Med J, 54(6): 398-401. doi: $10.4103 / 0300-1652.126294$.

[22] WHO (n.d.). Global Alert and Response: Recommended Surveillance Standards ( $2^{\text {nd }}$ ed.). WHO/CDS/CSR/ISR/99.2 Retrieved from http://www.who.int/csr/resources/publications/surveillance/wh ocdscsrisr992.pdf.

[23] WHO (1992). Traditional birth attendants. A joint WHO/UNFPA/UNICEF statement, WHO, Geneva.

[24] National Population Commission (NPC) [Nigeria] and ICF Macro. 2009. Nigeria Demographic and Health Survey 2008. Abuja, Nigeria: National Population Commission and ICF Macro. Retrieved from http://nigeria.unfpa.org/pdf/nigeriadhs2008.pdf.

[25] Saleh, J-E. A., Adamu, H. I., \& Ningi, A. I. (2015). NNT Elimination and the Nigeria's Health System: Where is the Missing Link? Science Journal of Public Health (In press). 